\title{
POTENSI PEMANFAATAN TANAMAN NANAS KERANG-BUAH JERUK NIPIS SEBAGAI PRODUK MINUMAN FUNGSIONAL DENGAN APLIKASI TEKNOLOGI PASTEURISASI
}

\author{
Sumarto $^{1}$, Deris Aprianty ${ }^{2}$ \\ 1, 2, Dosen Jurusan Gizi Poltekkes Kemenkes Tasikmalaya
}

\begin{abstract}
ABSTRAK
Nanas Kerang merupakan salah satu jenis tanaman yang banyak ditanam di Indonesia. Akan tetapi, secara ilmiah belum banyak penelitian di Indonesia yang menggali kandungan komponen bioaktif Nanas Kerang yang berpengaruh terhadap kesehatan dan pemanfaatannya menjadi produk pangan. Penelitian di luar negeri telah membuktikan bahwa Nanas Kerang bermanfaat dalam mencegah kanker. Untuk itu, perlu dilakukan pemanfaatan Nanas Kerang menjadi produk pangan fungsional agar dapat dikonsumsi oleh masyarakat yang lebih luas. Pembuatan produk tersebut dapat dilakukan dengan aplikasi teknologi pasteurisasi yang sederhana dengan penambahan Jeruk Nipis untuk menurunan $\mathrm{pH}$ produk agar sesuai dengan standar proses pasteurisasi. Jenis penelitian yang digunakan adalah eksperimen murni dengan Rancangan Acak Kelompok. Variabel bebas penelitian adalah perbandingan Nanas Kerang dan Jeruk Nipis yaitu penambahan air perasan jeruk nipis 1,5\%, 2,0\%, 2,5\%, dan 3,0\%. Variabel terikatnya adalah mutu organoleptik (warna, rasa, aroma, dan tekstur/kekentalan) dan keasaman $(\mathrm{pH})$ produk. Hasil penelitian menunjukkan bahwa produk minuman nanas kerang jeruk nipis dapat dibuat dengan aplikasi teknologi pasteurisasi dengan suhu $80^{\circ} \mathrm{C}$ selama 15 menit dikarenakan produk yang dihasilkan memiliki pH 3-3,5. Penambahan air perasan jeruk nipis mempengaruhi tingkat kesukaan panelis terhadap minuman nanas kerang terutama pada parameter warna dan rasa. Perlakuan terbaik dari seluruh paramater adalah penambahan air perasan jeruk nipis $3,0 \%$.
\end{abstract}

Kata kunci: Jeruk nipis, Nanas kerang, Organoleptik, Pasteurisasi, pH

\begin{abstract}
Rhoeo discolor is one of plants grown in Indonesia. However, in Indonesia, research that explores the content of bioactive components in Rhoeo discolor and its influence on health and its utilization into food products has not been much. In other country, result of research has shown that Rhoeo discolor beneficial in preventing cancer. For it is, Rhoeo discolor need to be developed into a functional food product that can be consumed by the public. The manufacture of these products can be done with a pasteurization technology with the addition of Lime to $\mathrm{pH}$ decreased the product to conform to standard pasteurization process. This type of research is a true experiment with randomized block design. The independent variable was the comparison of Rhoeo discolor and Lime with the addition of lime juice 1.5\%, $2.0 \%, 2.5 \%$, and $3.0 \%$. The dependent variable is the organoleptic properties (color, taste, aroma, and texture/viscosity) and acidity $(\mathrm{pH})$ of the product. The results showed that the product Rhoeo discolor-Lime drinks can be made by pasteurization technology with a temperature of $80{ }^{\circ} \mathrm{C}$ for 15 minutes due to the resulting product has a $\mathrm{pH}$ of 3-3.5. The addition of lime juice affects the preference level panelists to Rhoeo discolor drink mainly on the color and flavor parameters. The best treatment of all parameters is the addition of lime juice $3.0 \%$.
\end{abstract}

Key words: Lime, Rhoeo discolor, Organoleptic, Pasteurization, $\mathrm{pH}$ 


\section{PENDAHULUAN}

Indonesia merupakan salah satu negara yang memiliki kekayaan biodiversitas dengan berbagai macam tanaman obat yang dihasilkan dari tanah air ini. Ratusan bahkan ribuan tanaman obat ini telah ditemukan memiliki manfaat secara empirik bagi kesehatan tubuh. Akan tetapi, belum semua jenis tanaman obat tersebut telah diuji secara ilmiah untuk melihat kandungan komponen bioaktif yang bermanfaat bagi kesehatan.

Salah satu tanaman obat yang belum termanfaatkan dengan baik adalah Nanas Kerang (Rhoeo discolor). Secara empirik, nanas kerang memiliki manfaat untuk menyembuhkan penyakit bronkhitis, batuk, TBC kelenjar, mimisan, disentri, dan berak darah (Anonim $^{\mathrm{a}}$, 2014). Penelitian secara ilmiah di luar negeri yang dilakukan oleh Rosales-Reyes, et al. (2007) menunjukkan bahwa ekstrak utuh dengan pelarut air dari Nanas Kerang (Rhoeo discolor) dapat mencegah terjadinya kanker. Sedangkan penelitian Boffill-Càrdenas et al. (2006) menunjukkan bahwa Nanas Kerang mempunyai efek diuretik. Ekstrak larut air dari Nanas Kerang dapat memblok aktivitas antiadregenerik dari bretylium (Garc'ıa et al., 1971) dan kontraseptif pada tikus (Weniger et al., 1982). Ekstrak Nanas Kerang yang dibuat sebagai bahan kosmetik dapat meningkatkan penampilan kulit (Meybeck et al., 1999). Pada ekstrak larut alkohol, Nanas Keras secara in vitro menunjukkan aktivitas antimutagenik, antigenotoksik, dan antioksidatif (Gonza'lez$A^{\prime}$ vila et al., 2003).

Salah satu komponen bioaktif yang terdapat di dalam Nanas Kerang adalah Antosianin, suatu pigmen yang memberikan warna ungu pada daun Nanas Kerang pada

\section{METODE PENELITIAN}

Jenis penelitian yang digunakan dalam penelitian ini adalah eksperimen murni dengan menggunakan rancangan acak kelompok dengan 4 perlakuan. Perlakuan penelitian yang diterapkan dalam pembuatan minuman fungsional adalah sisi belakangnya. Menurut Winarno (2008) pigmen antosianin memberikan warna merah, biru, violet, dan biasanya dijumpai pada bunga, buah-buahan, dan sayursayuran. Menurut Yashinaga (1995) Antosianin dapat menghalangi munculnya sel kanker serta baik untuk dikonsumsi oleh penderita jantung koroner.

Berdasarkan manfaat yang dimiliki oleh Nanas Kerang tersebut, perlu dikembangkan suatu produk pangan yang dapat dikonsumsi secara luas dari bahan baku Nanas Kerang. Salah satu produk yang dapat dikembangkan adalah berupa pangan (minuman) fungsional, yaitu pangan olahan yang mengandung satu atau lebih komponen fungsional yang berdasarkan kajian ilmiah mempunyai fungsi fisiologis tertentu, terbukti tidak membahayakan dan bermanfaat bagi kesehatan (BPOM, 2005).

Pembuatan produk minuman fungsional dari bahan baku Nanas Kerang perlu dilakukan melalui proses pengolahan yang tepat agar kandungan komponen bioaktif dapat dipertahankan sekaligus memperpanjang masa simpan produk, sehingga dapat dimanfaatkan lebih luas oleh masyarakat. Salah satu proses yang dapat diterapkan adalah dengan teknologi pasteurisasi. Sebuah teknologi sederhana yang dapat diterapkan oleh masyarakat luas dengan aplikasi proses thermal dengan menggunakan suhu di bawah $100{ }^{\circ} \mathrm{C}$.

Proses pasteurisasi membutuhkan persyaratan sifat produk dengan nilai $\mathrm{pH}$ maksimal 4,6. Sehingga perlu adanya penambahan bahan baku yang dapat menurunkan nilai $\mathrm{pH}$ produk, salah satu bahan tersebut adalah Jeruk Nipis. Menurut Exteberria, et al. (2003) jeruk nipis memiliki kandungan asam dengan $\mathrm{pH} 2,0$.

perbandingan Nanas Kerang dan Jeruk Nipis sebagai bahan utama yaitu perlakuan A, B, C, dan D dengan masing-masing penambahan air perasan jeruk nipis sebanyak $1,5 \%, 2,0 \%, 2,5 \%$, dan $3,0 \%$ berdasarkan air ekstrak daun Nanas 
Kerang. Sebelumnya dilakukan penelitian pendahuluan untuk menetapkan komposisi bahan baku yang lebih tepat.

Tanaman Nanas Kerang diambil dari kampus Poltekkes Kemenkes Tasikmalaya. Proses pembuatan minuman dibagi menjadi 2 tahap, yaitu pembuatan ekstrak Nanas Kerang dan pembuatan minuman fungsional Nanas Kerang - Jeruk Nipis. Pembuatan ekstrak Nanas Kerang mengikuti metode yang dikembangkan oleh Rosales-Reyes, et al. (2007) dengan modifikasi. Pembuatan minuman fungsional Nanas Kerang - Jeruk Nipis mengadopsi dari modifikasi pembuatan minuman isotonik yang dilakukan oleh Roji (2006). Uji organoleptik

\section{HASIL}

\section{Penelitian Pendahuluan dan Standar Proses Pembuatan Minuman Nanas Kerang}

Penelitian Pendahuluan dilakukan untuk menetapkan perlakuan dan proses pada penelitian utama. Penelitian pendahuluan dilakukan untuk memperoleh jumlah bahan baku yang akan digunakan dalam pembuatan minuman Nanas Kerang - Jeruk Nipis. Bahan baku yang digunakan pada penelitian pendahuluan adalah daun Nanas Kerang, Jeruk Nipis, Air, dan Gula. Jumlah Nanas Kerang yang digunakan pada penelitian pendahuluan disesuaikan dengan warna yang dihasilkan setelah proses ekstraksi. Pada penelitian pendahuluan tersebut diperoleh jumlah daun Nanas Kerang yang digunakan adalah 50 helai dengan berat rata-rata 165 gram.

Jumlah air yang digunakan dalam penelitian pendahuluan adalah $3000 \mathrm{ml}$. Air tersebut jumlahnya berkurang hingga 2500 $\mathrm{ml}$ setelah proses ekstraksi daun Nanas Kerang selama 30 menit. Jumlah air hasil ekstraksi tersebut digunakan sebagai dasar dalam perhitungan penambahan bahan baku lain yaitu gula dan air perasan jeruk nipis.

Jumlah gula yang ditambahkan adalah $12 \%$ dari jumlah air hasil ekstraksi yaitu sebanyak 300 gram. Persentase gula tesebut digunakan berdasarkan standar dilakukan menurut Meilgaard, et al. (1999). Parameter yang dinilai pada uji organoleptik meliputi warna, rasa, aroma, dan kekentalan. Uji organoleptik menggunakan hedonic scale test dan panelis tidak terlatih sebanyak 30 orang. Instrumen penelitian yang digunakan terdiri atas peralatan yang dibutuhkan dalam pembuatan minuman fungsional Nanas Kerang - Jeruk Nipis, kuesioner uji organoleptik hedonik, dan $\mathrm{pH}$ indikator untuk mengukur keasaman $(\mathrm{pH})$. Data hasil organoleptik yang diperoleh kemudian diolah dan dianalisis dengan menggunakan program perangkat lunak statistik.

pada minuman pada umumnya yang mengandung gula (sukrosa) hingga 12\% dan memiliki ${ }^{\circ}$ Brix 12 juga. Jumlah air perasan jeruk nipis yang digunakan pada penelitian pendahuluan adalah 50 gram atau sebesar $2.0 \%$ dari jumlah air hasil ekstraksi Nanas Kerang.

Berdasarkan formulasi dan komposisi bahan tersebut di atas menunjukkan bahwa minuman Nanas Kerang - Jeruk Nipis yang dihasilkan memiliki penerimaan yang cukup baik oleh sejumlah panelis (5 orang). Hasil pengukuran $\mathrm{pH}$ produk minuman Nanas Kerang dari uji pendahuluan adalah 3 , sehingga formula ini dapat digunakan sebagai syarat dalam aplikasi pasteurisasi.

Formulasi di atas dijadikan sebagai dasar dalam penetapan formulasi untuk penelitian utama. Perlakuan yang digunakan pada penelitian utama adalah dengan mengurangi dan menambahkan persentase air perasan jeruk nipis dari formula pada penelitian pendahuluan. Sehingga digunakan persentase $1,5 \%, 2,0 \%, 2,5 \%$, dan $3,0 \%$. Penetapan standar proses pembuatan minuman Nanas Kerang - Jeruk Nipis dapat dilihat pada Gambar 1. Tanaman Nanas Kerang sebagai bahan baku utama dan produk minuman yang dihasilkan dalam penelitian dapat dilihat pada Gambar 2. 


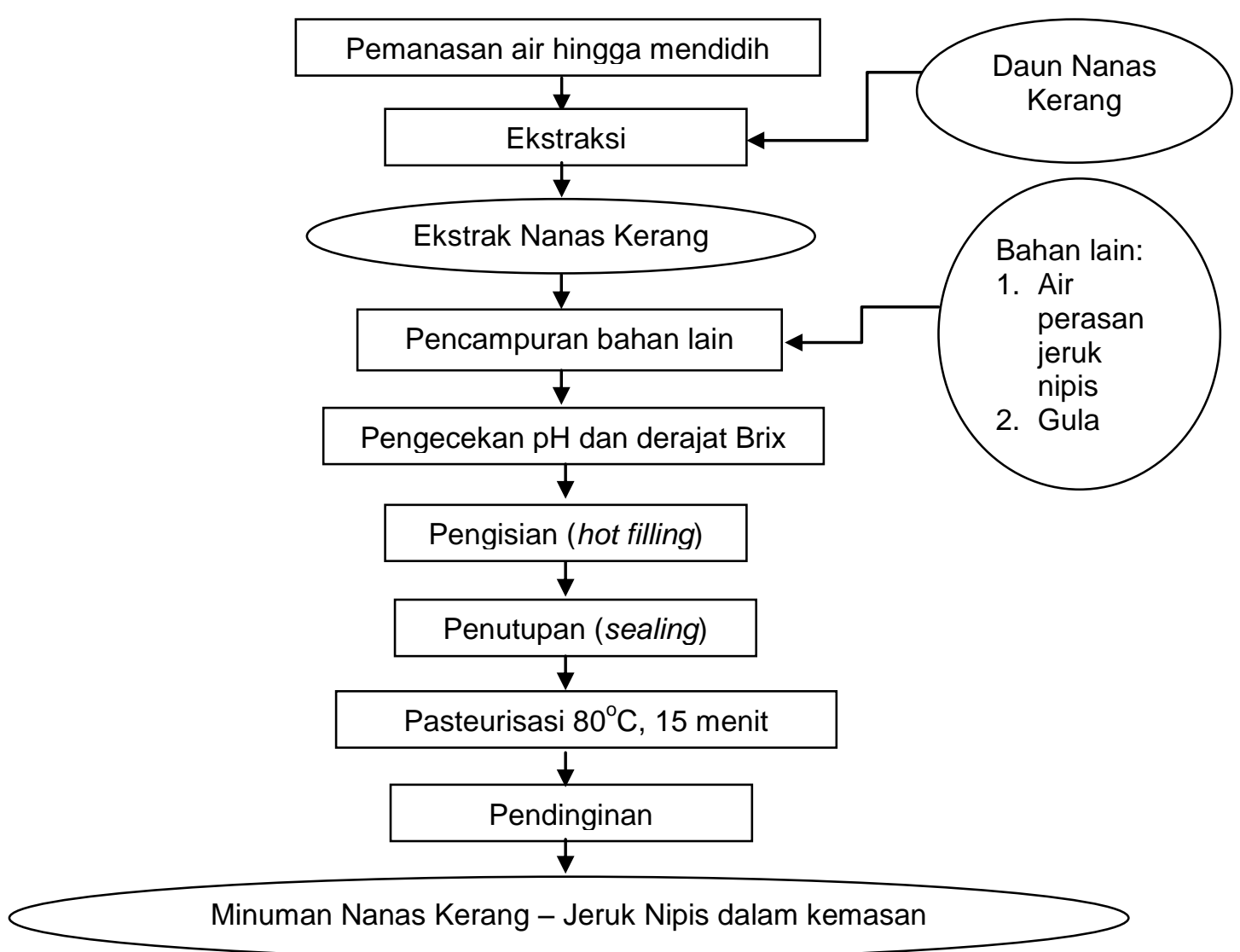

Gambar 1. Proses Pembuatan Minuman Nanas Kerang - Jeruk Nipis

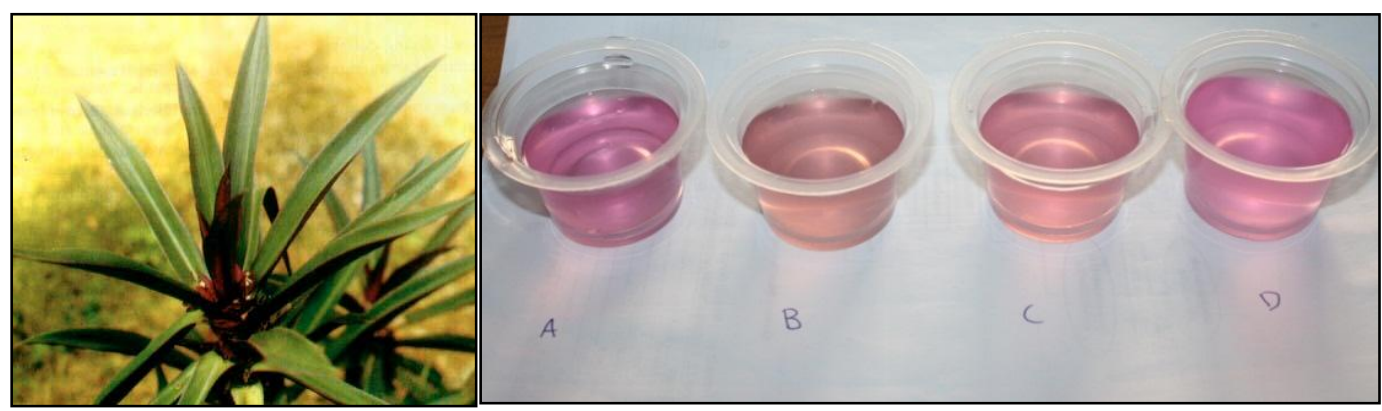

Gambar 2. Tanaman Nanas Kerang dan Produk Minuman Hasil Penelitian

\section{Sifat Organoleptik Minuman Nanas} Kerang - Jeruk Nipis

a) Tingkat Kesukaan terhadap Warna

Hasil uji tingkat kesukaan panelis terhadap warna minuman nanas kerang jeruk nipis secara deskriptif dapat dilihat pada Gambar 3. Data kemudian diolah dan dianalisis dengan uji secara statistik untuk melihat signifikansi perbedaan penilaian kesukaan terhadap paramater warna minuman nanas kerang - jeruk nipis untuk masing-masing perlakuan. Hasil uji statistik dengan menggunakan Kruskal Wallis diperoleh nilai $\mathrm{P}<0.05(\mathrm{P}=0.000)$, artinya terdapat perbedaan yang signifikan pada penilaian kesukaan warna minuman nanas kerang - jeruk nipis. Kemudian dilakukan uji lanjut dengan $U$ Mann Whitney dengan $\alpha=$ 0,05 . Hasil uji tersebut dapat dilihat pada Tabel 1. 


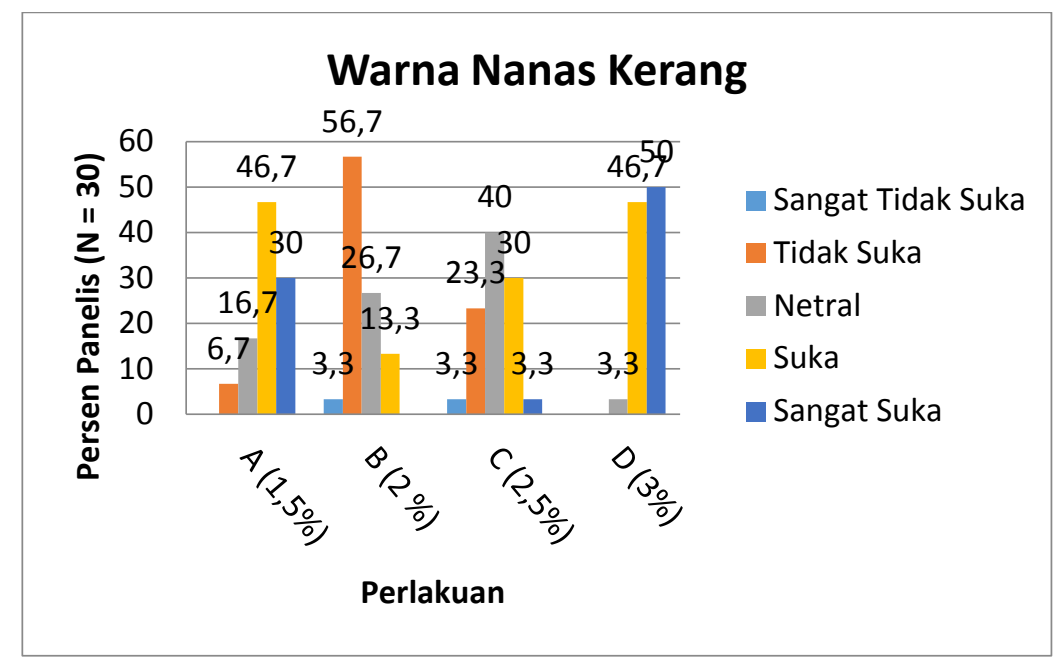

Gambar 3. Tingkat Kesukaan terhadap Warna Minuman Nanas Kerang

Tabel 1. Hasil Analisis U Mann Whitney Tingkat Kesukaan terhadap Warna Minuman Nanas Kerang - Jeruk Nipis

\begin{tabular}{|c|c|c|c|}
\hline \multicolumn{2}{|c|}{ Formula } & \multirow{2}{*}{$\frac{\mathbf{P}}{0.000}$} & \multirow{2}{*}{$\frac{\text { Keterangan }}{\text { Signifikan }}$} \\
\hline A & $B$ & & \\
\hline & C & 0.000 & Signifikan \\
\hline & $\mathrm{D}$ & 0.031 & Signifikan \\
\hline \multirow[t]{2}{*}{$B$} & $C$ & 0.011 & Signifikan \\
\hline & $\mathrm{D}$ & 0.000 & Signifikan \\
\hline$C$ & $D$ & 0.000 & Signifikan \\
\hline
\end{tabular}

b) Tingkat Kesukaan terhadap Aroma

Berdasarkan hasil penilaian secara deskriptif, hasil uji tingkat kesukaan terhadap aroma minuman Nanas Kerang - Jeruk Nipis dapat dilihat pada Gambar 4.

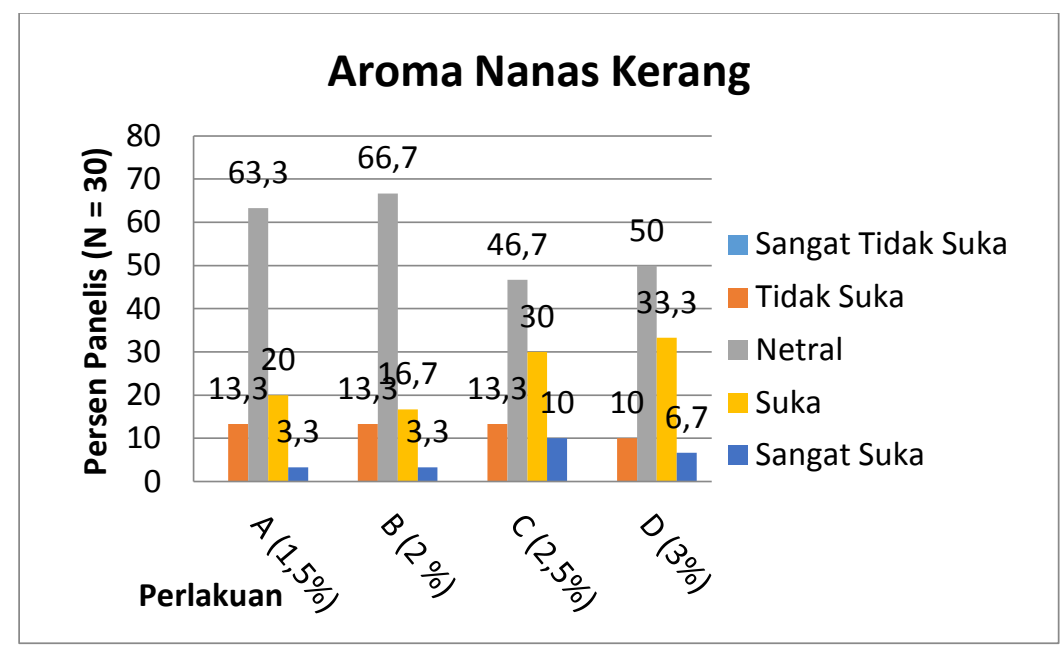

Gambar 4. Tingkat Kesukaan terhadap Aroma Minuman Nanas Kerang 
Data tersebut kemudian diolah dan dianalisis secara statistik. Berdasarkan uji statistik dengan menggunakan Kruskal Wallis diperoleh nilai $P>0,05(P=0.317)$ artinya tidak terdapat perbedaan yang signifikan pada penilaian aroma minuman nanas kerang - jeruk nipis dari semua perlakuan, sehingga tidak perlu dilakukan uji lanjut.

c) Tingkat Kesukaan terhadap Kekentalan

Hasil penilaian secara deskriptif, hasil uji tingkat kesukaan terhadap kekentalan minuman nanas kerang - jeruk nipis dapat dilihat pada Gambar 5.

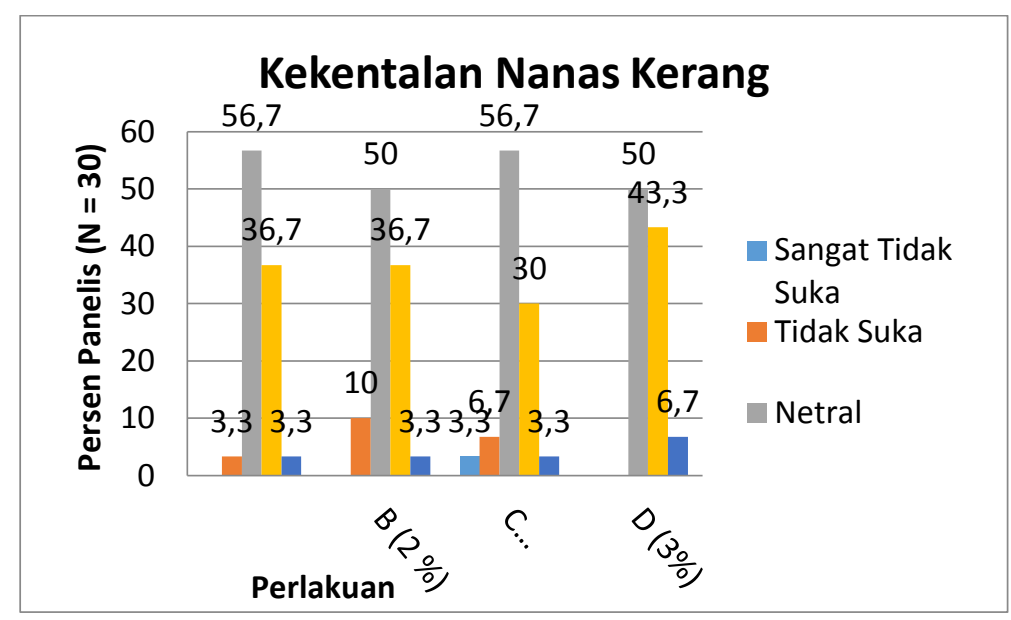

Gambar 5. Tingkat Kesukaan terhadap Kekentalan Minuman Nanas Kerang

Data tersebut kemudian diolah dan dianalisis secara statistik. Hasil uji statistik dengan menggunakan Kruskal Wallis diperoleh nilai $P>0.05(P=0.393)$, artinya tidak terdapat perbedaan yang signifikan pada penilaian kekentalan minuman nanas kerang - jeruk nipis dari semua perlakuan, sehingga tidak perlu dilakukan uji lanjut.

d) Tingkat Kesukaan terhadap Rasa

Berdasarkan hasil penilaian secara deskriptif, hasil uji tingkat kesukaan terhadap rasa minuman Nanas Kerang - Jeruk Nipis dapat dilihat pada Gambar 6.

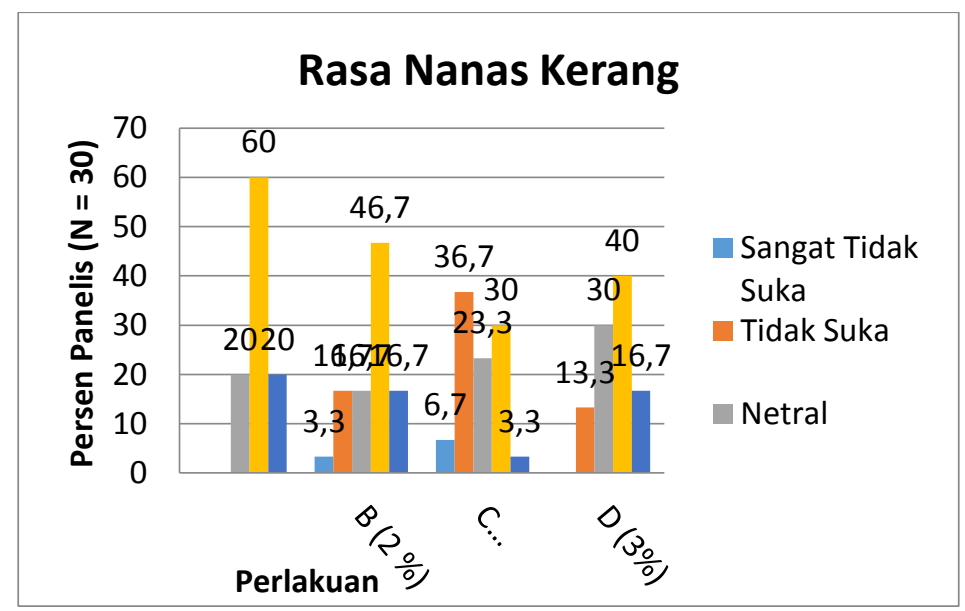

Gambar 6. Tingkat Kesukaan terhadap Rasa Minuman Nanas Kerang 
Data tersebut kemudian diolah dan dianalisis secara statistik. Berdasarkan hasil uji statistik dengan menggunakan Kruskal Wallis diperoleh nilai $\mathrm{P}<0.05(\mathrm{P}=0.000)$, artinya terdapat perbedaan yang signifikan pada penilaian kesukaan rasa minuman nanas kerang - jeruk nipis. Kemudian dilakukan uji lanjut dengan $U$ Mann Whitney dengan $\alpha=0,05$. Hasil uji tersebut dapat dilihat pada Tabel 2.

Tabel 2. Hasil Analisis U Mann Whitney Tingkat Kesukaan terhadap Rasa Minuman Nanas Kerang

\begin{tabular}{cccc}
\hline & Formula & P & Keterangan \\
\hline A & B & 0.146 & Non Signifikan \\
& C & 0.000 & Signifikan \\
& D & 0.084 & Non Signifikan \\
\hline B & C & 0.013 & Signifikan \\
& D & 0.925 & Non Signifikan \\
\hline C & D & 0.009 & Signifikan \\
\hline
\end{tabular}

\section{Keasaman Produk Minuman Nanas Kerang - Jeruk Nipis}

Keasaman produk diukur dengan menilai pH. Produk minuman Nanas Kerang - Jeruk Nipis yang dihasilkan memiliki nilai $\mathrm{pH}$ yang berbeda pada masing-masing perlakuan. Hasil pengukuran $\mathrm{pH}$ minuman Nanas Kerang - Jeruk Nipis dapat dilihat pada Tabel 3.

Tabel 3. Nilai pH Minuman Nanas Kerang - Jeruk Nipis

\begin{tabular}{cc}
\hline Perlakuan & Nilai pH \\
\hline A $(1,5 \%)$ & 3,5 \\
B $(2,0 \%)$ & 3 \\
C $(2,5 \%)$ & 3 \\
D $(3,0 \%)$ & 3 \\
\hline
\end{tabular}

\section{Perlakuan Terbaik}

Penilaian secara deskriptif dari keseluruhan parameter untuk mencari perlakuan terbaik dapat dilihat pada Gambar 7.

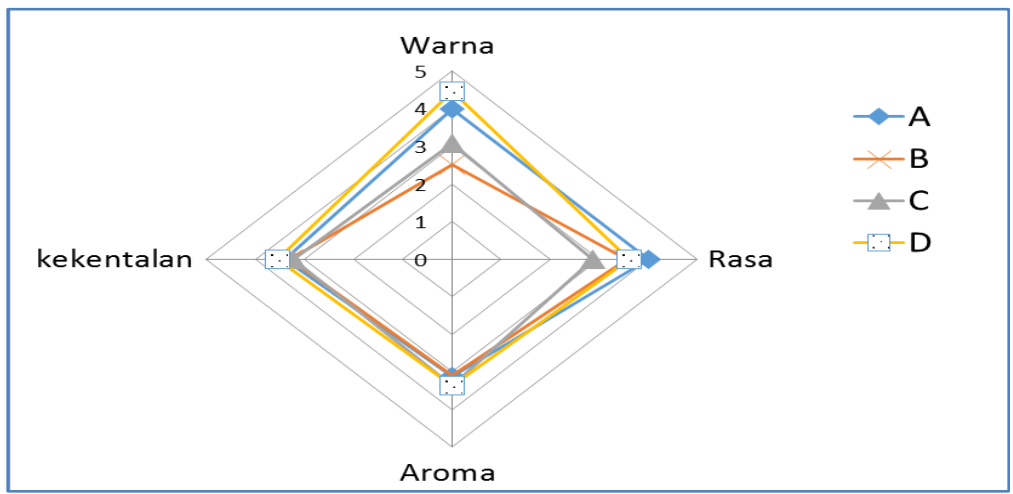

Gambar 7. Penilaian terhadap Keseluruhan Parameter Minuman Nanas Kerang 
Hasil penilaian secara keseluruhan berdasarkan data statistik dapat dilihat pada Tabel 4 .

Tabel 4. Penilaian Mean Rank terhadap Keseluruhan Paramater Minuman Nanas Kerang

\begin{tabular}{|c|c|c|c|c|c|}
\hline Parameter & Perlakuan & A & B & C & D \\
\hline Warna & & $75,35^{a}$ & $29,90^{b}$ & $46,37^{c}$ & $90,38^{d}$ \\
\hline Aroma & & $56,02^{\mathrm{a}}$ & $54,38^{\mathrm{a}}$ & $65,42^{\mathrm{a}}$ & $66,18^{a}$ \\
\hline Kekentalan & & $60,75^{\mathrm{a}}$ & $58,42^{\mathrm{a}}$ & $54,70^{\mathrm{a}}$ & $68,13^{a}$ \\
\hline Rasa & & $76,00^{\mathrm{a}}$ & $63,08^{\mathrm{ab}}$ & $40,55^{c}$ & $62,37^{\mathrm{abd}}$ \\
\hline
\end{tabular}

Keterangan: notasi huruf yang berbeda (a,b, dst.) secara statistik menunjukkan perbedaan yang signifikan pada $\alpha=0,05$.

\section{PEMBAHASAN}

\section{Penelitian Pendahuluan dan Standar Proses Pembuatan Minuman Nanas Kerang}

Metode pasteurisasi merupakan tahapan yang sangat penting sebagai proses pengawetan pada minuman Nanas Kerang. Hasil penelitian pendahuluan menunjukkan bahan dan proses yang digunakan sesuai dengan persyaratan aplikasi pasteurisasi. Salah satu syarat proses pengawetan pangan dengan metode pasteurisasi adalah pH produk di bawah 4,5 (Fellows, 2000). Minuman Nanas Kerang dengan penambahan air perasan Jeruk Nipis minimal 1,5\% memiliki pH produk 3 . Artinya, syarat untuk dilakukan proses pasteurisasi pada produk tersebut terpenuhi. Pasteurisasi dilakukan pada suhu $80{ }^{\circ} \mathrm{C}$ selama 15 menit. Semakin tinggi suhu yang digunakan, maka akan semakin pendek waktu yang diperlukan dalam proses pasteurisasi. Perlakuan penambahan air perasan jeruk nipis sebanyak $1,5 \%, 2,0 \%$, $2,5 \%$, dan $3 \%$ juga sesuai dengan kategori pangan menurut BPOM (2006) yang mensyaratkan bahwa minuman jeruk mengandung $1,5 \%$ hingga $2 \%$ sari buahnya.

\section{Sifat Organoleptik Minuman Nanas Kerang - Jeruk Nipis}

a) Tingkat Kesukaan terhadap Warna

Warna sering kali mempengaruhi respon dan persepsi panelis, karena warna merupakan atribut sensori yang pertama dinilai melalui indra penglihatan. Pada produk minuman nanas kerang dengan penambahan air jeruk nipis ini menghasilkan warna merah muda. Semakin tinggi persentase air jeruk nipis yang dicampurkan, semakin cerah warna merah muda yang dihasilkan.

Berdasarkan hasil pada Gambar 3, warna sampel $A, C$ dan $D$ menjadi sampel yang lebih disukai karena warnanya lebih menarik. Sedangkan sampel B menjadi sampel yang banyak tidak disukai karena warnanya menjadi gelap. Berdasarkan uji statistik juga menggambarkan bahwa penilaian panelis terhadap warna minuman Nanas Kerang - Jeruk Nipis memiliki perbedaan yang signifikan antar perlakuan. Perubahan warna secara signifikan dipengaruhi oleh penambahan air perasan jeruk nipis. Penambahan air jeruk nipis tersebut dapat menurunkan $\mathrm{pH}$ minuman nanas kerang. Warna dari minuman tersebut akan berubah tergantung pada $\mathrm{pH}$. Kestabilan pigmen antosianin yang dihasilkan nanas kerang tergantung pada $\mathrm{pH}$ produk. Perubahan $\mathrm{pH}$ dapat menyebabkan struktur dari antiosianin yang akan merubah warna serta kestabilannya. Antosianin akan berwarna merah pada $\mathrm{pH}$ asam $(\mathrm{pH}<3)$. Warna kemudian akan menjadi ungu atau biru pada $\mathrm{pH}$ basa dan kemungkinan akan kehilangan warna apabila pHnya terus naik (Winarno, 2008).

b) Tingkat Kesukaan terhadap Aroma

Bau atau aroma merupakan sifat sensori yang paling sulit untuk diklasifikasikan dan dijelaskan karena ragamnya yang begitu besar (Setyaningsih, dkk., 2010). Aroma dari minuman nanas kerang - jeruk nipis yang dihasilkan tidak 
hanya ditentukan oleh satu bahan tetapi dipengaruhi juga oleh beberapa bahan yang memiliki bau khas sendiri serta perbandingan bahan yang digunakan, seperti jeruk nipis dan gula. Hasil di atas menunjukkan bahwa penambahan jumlah air perasan jeruk nipis tidak berpengaruh terhadap penerimaan panelis pada parameter aroma minuman nanas kerang. Hal ini dapat dikarenakan perbedaan jumlah penambahan air perasan jeruk nipis yang tidak terlalu jauh berbeda, sehingga aroma yang dihasilkan minuman nanas kerang juga tidak beda signifikan antar perlakuan.

c) Tingkat Kesukaan terhadap Kekentalan

Berdasarkan hasil uji organoleptik di atas menunjukkan bahwa penambahan air perasan jeruk nipis tidak mempengaruhi kesukaan panelis terhadap kekentalan minuman nanas kerang. Hal ini dapat diartikan bahwa penambahan air perasan jeruk nipis dari $1,5 \%$ hingga 3,0\% memiliki kekentalan yang tidak beda signifikan. Salah satu parameter yang dapat melihat kekentalan produk minuman adalah total padatan terlarut. Bahan yang mempengaruhi kandungan total padatan terlarut dalam minuman nanas kerang adalah gula. Jumlah gula yang digunakan pada produk ini adalah sama, sehingga kekentalan minuman yang dihasilkannya juga tidak berbeda signifikan.

d) Tingkat Kesukaan terhadap Rasa

Indra pencicip berfungsi untuk menilai rasa dari suatu makanan. Berdasarkan hasil uji organoleptik menunjukkan bahwa penambahan air perasan jeruk nipis mempengaruhi kesukaan terhadap rasa minuman nanas kerang. Hal ini dikarenakan air perasan jeruk nipis memberikan rasa asam yang cukup kuat, menurut Anonimb (2014) buah jeruk nipis yang sudah tua rasanya asam.

\section{Keasaman Produk Minuman Nanas Kerang - Jeruk Nipis \\ Berdasarkan Tabel 3 dapat dilihat bahwa semakin tinggi penambahan air perasan jeruk nipis, maka nilai $\mathrm{pH}$ minuman nanas kerang yang dihasilkan semakin}

rendah. Hal ini sesuai dengan penelitian Exteberria, et al. (2003) bahwa jeruk nipis memiliki $\mathrm{pH}$ yang asam yaitu 2. Sehingga semakin banyak jeruk nipis yang ditambahkan maka akan menurunkan $\mathrm{pH}$ minuman nanas kerang tersebut.

Keasaman minuman nanas kerang yang dihasilkan akan mempengaruhi warna yang dihasilkan. Hal ini karena antosianin pada nanas kerang akan berubah warna dari merah, ungu, hingga biru tergantung pada $\mathrm{pH}$ produk (Winarno, 2008).

\section{Perlakuan Terbaik}

Pemilihan perlakuan terbaik diperoleh berdasarkan hasil penilaian secara organoleptik dari keseluruhan paramater yang diuji. Penilaian secara keseluruhan merupakan penilaian yang dilihat dari ke empat parameter (warna, aroma, kekentalan, dan rasa) yang digunakan untuk melihat produk minuman nanas kerang jeruk nipis atau perlakuan mana yang paling disukai dan dapat diterima.

Berdasarkan Gambar 7 dapat dilihat bahwa minuman nanas kerang dengan perlakuan $\mathrm{D}$ (penambahan air jeruk nipis $3 \%)$ paling banyak disukai. Dari ke empat parameter, minuman nanas kerang perlakuan $D$ paling disukai dari segi warna, aroma, dan kekentalan. Sedangkan untuk rasa minuman nanas kerang $\mathrm{A}$ (penambahan air jeruk nipis $1,5 \%$ ) yang paling disukai.

Data pada Tabel 4 menunjukkan bahwa nilai Mean Rank yang tertinggi merupakan minuman nanas kerang yang paling banyak disukai. Sehingga dapat dilihat bahwa minuman nanas kerang dengan perlakuan $\mathrm{D}$ memiliki nilai mean rank paling tinggi pada parameter warna 90,38, aroma 66,18, dan kekentalan 68,13. Sedangkan paramater rasa penilaian pada perlakuan $D$ tidak beda signifikan dengan perlakuan $\mathrm{A}$ yang memiliki nilai mean rank tertinggi. Sehingga dapat dikatakan bahwa perlakuan terbaik adalah dengan penambahan air perasan jeruk nipis 3\% (perlakuan D) pada semua paramater (warna, aroma, kekentalan, dan rasa). 


\section{KESIMPULAN}

Minuman nanas kerang - jeruk nipis dapat diolah menggunakan metode pasteurisasi dikarenkan nilai $\mathrm{pH}$ produk 33,5. Hasil uji organoleptik menunjukkan bahwa penambahan air perasan jeruk nipis

\section{SARAN}

Produk Minuman Nanas Kerang Jeruk Nipis dapat diaplikasikan kepada masyarakat berdasarkan hasil penelitian ini. Proses pembuatan minuman Nanas Kerang - Jeruk Nipis dapat dilakukan melalui proses pasteurisasi yang dapat diaplikasikan oleh masyarakat karena menggunakan teknologi

\section{REFERENSI}

Anonim ${ }^{a}$. 2014. Nanas Kerang (Rhoeo discolor). http://www.iptek.net.id/ind/ pd_tanobat/view.php?id=46 diakses 24 April 2014.

Anonim ${ }^{b}$. 2014. Jeruk Nipis (Citrus aurantifolia, Swingle.). http://www.iptek.net.id/ind/pd_tanobat/vi ew.php?id=131 diakses 24 April 2014.

BPOM [Badan Pengawas Obat dan Makanan] RI. 2005. Peraturan Kepala BPOM Nomor HK 00.05.52.0685 tentang Ketentuan Pokok Pengawasan Pangan Fungsional.

BPOM [Badan Pengawas Obat dan Makanan] RI. 2006. Peraturan Kepala BPOM Nomor HK 00.05.52.4040 tentang Kategori Pangan.

Boffill-Cárdenas, Maria, Geidy Lorenzo Monteagudo, Emilio Monteagudo Jiménez, Mario Suerio Oyarzum, Yamilet Martinez Chavian, Jesus Matos J, Sulay Loy. 2006. Diuretic Activity Of Five Medicinal Plants Used Popularly In Cuba. Pharmacologyonline 3: 435-441.

Fellows, P. J. 2000. Food Processing Technology 2nd ed. CRC Press, New York.

Garc'ıa, M., Miyares, C., Men'endez, E., Sainz, F., 1971. Blockade of the antiadrenergic action of bretylium by an aqueous extract of the leaves of Rhoeo spathacea. Canadian Journal of mempengaruhi kesukaan minuman nanas kerang, terutama dari parameter warna dan rasa. Perlakuan yang dapat diterima dan paling disukai oleh panelis adalah dengan penambahan air perasan jeruk nipis 3,0\%.

yang sederhana. Penelitian selanjutnya dapat dilakukan dengan mengukur dan menganalisis kandungan komponen bioaktif pada minuman Nanas Kerang - Jeruk Nipis untuk memperkuat klaim sebagai pangan fungsional.

Physiology and Pharmacology 49,1106-1110.

Gonza'lez-A' vila, M., Arriaga-Alba, M., De la Garza, M., Herna'ndez-Pretel'ın, M.C., Dom'ınguez-Ort'ız, M.A., FattelFazenda, S., Villa-Trevĩno, S., 2003. Antigenotoxic, antimutagenic and ROS scavenging activities of a Rhoeo discolor ethanolic crude extract. Toxicology in Vitro 17, 77-83.

Meilgaard M, Civille GV, dan Carr BT. 1999. Sensory Evaluation Techniques 3rd Edition. CRC Press, Boca Raton.

Meybeck, A., Potier, P., Bonte, F., Picot, F., Cosson, J.P., 1999. Use of the Rhoeo discolor plant extracts in cosmetics and pharmaceutics, in particular in dermatology. Patent abstracts of France, FR2767690.

Roji, Fahrul. 2006. Pembuatan Produk Minuman Isotonik (Isotonic Drink) dalam Kemasan Gelas Plastik Di PT. Fits Mandiri Bogor. Skripsi. Fakultas Teknologi Pertanian IPB, Bogor.

Rosales-Reyes, T'abata, Mireya de la Garza, Carlos Arias-Castro, Martha Rodr'Iguez-Mendiola, Samia FattelFazenda, Evelia Arce-Popoca, Sergio Hern'andez-Garc'ıa, Sa'ul VillaTreviĩno. 2007. Aqueous crude extract of Rhoeo discolor, a Mexican medicinal plant, decreases the formation of liver 
preneoplastic foci in rats. Journal of Ethnopharmacology 115 (2008) 381386.

Setyaningsih, D., A. Apriantono., M.P. Sari. 2010. Analisis Sensori untuk Industri Pangan dan Agro. IPB Press, Bogor.

Winarno, F.G. 2008. Kimia Pangan dan Gizi. Mbrio Press, Bogor.

Yashinaga, M. 1995. New Cultivar „Ayamurasaki" for Colorant Production. Sweetpotato Res. Front, Vol 1: 2.

Weniger, B., Haag-Berrurier, M., Anton, R., 1982. Plants of Haiti used as antifertility agents. Journal of Ethnopharmacology 6, 67-84. 